\title{
Composição química, atividade antimicrobiana do óleo essencial e ocorrência de esteróides nas folhas de Pterodon emarginatus Vogel, Fabaceae
}

\author{
Alexandre P. Santos, ${ }^{1}$ Daniel T. Zatta, ${ }^{1}$ Weuller F. Moraes, ${ }^{1}$ Maria Teresa F. Bara, ${ }^{1}$ \\ Pedro H. Ferri, ${ }^{2}$ Maria do Rosário R. Silva, ${ }^{3}$ José R. Paula ${ }^{* 1}$
}

\begin{abstract}
${ }^{1}$ Faculdade de Farmácia, Universidade Federal de Goiás, Caixa Postal 131, 74001-970 Goiânia-GO, Brasil, ${ }^{2}$ Instituto de Química, Universidade Federal de Goiás, Caixa Postal 131, 74001-970 Goiânia-GO, Brasil, ${ }^{3}$ Instituto de Patologia Tropical e Saúde Pública, Universidade Federal de Goiás, Caixa Postal 131, 74001-970 Goiânia-GO, Brasil.
\end{abstract}

\begin{abstract}
RESUMO: Pterodon emarginatus Vogel, Fabaceae, conhecida popularmente como sucupirabranca, é uma espécie arbórea que possui interesse como planta medicinal e fonte de madeira. Vários estudos com o óleo e extratos dos seus frutos demonstraram atividades cercaricida, antimicrobiana e antiinflamatória. Tendo em vista a importância de $P$. emarginatus como planta medicinal o presente trabalho analisou a composição química, a atividade antifúngica e antibacteriana do óleo essencial de suas folhas, isolou e identificou compostos do extrato etanólico bruto das folhas. A análise do óleo essencial das folhas permitiu a identificação de 9 hidrocarbonetos sesquiterpênicos, sendo os majoritários o $\gamma$-muuroleno $(48,79 \%)$ e o biciclogermacreno $(22,66 \%)$. O óleo essencial apresentou atividade frente a bactérias Gram-positivas, sendo inativo sobre isolados clínicos de Candida. O estudo fitoquímico do extrato etanólico das folhas permitiu o isolamento da mistura dos esteróides estigmasterol e $\beta$-sitosterol. Todos os resultados obtidos contribuem para a ampliação de informações sobre essa planta amplamente utilizada pela população.
\end{abstract}

Unitermos: Pterodon emarginatus, esteróides, óleo essencial, hidrocarbonetos sesquiterpênicos, sucupria-branca.

\begin{abstract}
Chemical composition, antimicrobial activity of essential oil and the occurrence of steroids in the leaves of Pterodon emarginatus Vogel, Fabaceae". Pterodon emarginatus Vogel, Fabaceae, known as "sucupira-branca", is a tree specie with interest as medicinal plant and source of wood. Several studies with the oil and fruit's extracts have been showed cercaricid, antimicrobial and antiinflamatory activities. The importance of $P$. emarginatus conducted the present study to realize evaluated antifungal and antibacterial activity of essential oil of their leaves, and isolated some compounds of ethanolic extract of the leaves. The analysis of the essential oil from leaves allowed the identification of nine sesquiterpenics hydrocarbons, with the majority $\gamma$-muurolene $(48.79 \%)$ and biciclogermacrene $(22.66 \%)$. The essential oil showed activity against the Gram-positive bacteria, and inactive on clinical isolates of Candida. The phytochemical study of the ethanol extract of the leaves allowed the isolation of the mixture of stigmasterol and $\beta$-sitosterol steroids. All results contribute to the expansion of information about this plant widely used by the population.
\end{abstract}

Keywords: Pterodon emarginatus, steroids, essential oil, sesquiterpenics hydrocarbons, sucupira-branca.

\section{INTRODUÇÃO}

A família Leguminosae, também designada de Fabaceae, pertence à ordem Fabales com cerca de 650 gêneros e 18000 espécies (Polhill, 1981, Judd et al.,
1999, Souza \& Lorenzi, 2005). No Brasil são encontrados cerca de 200 gêneros e 1500 espécies. No bioma Cerrado, constitui a família mais representativa em número, com cerca de 777 espécies, distribuídas em aproximadamente 101 gêneros (Ratter et al., 1977, Mendonça et al., 1998). 
Segundo Solereder (1908), a família Leguminosae abrange anatomicamente três subfamílias: Papilionoideae (Faboideae), Caesalpinoideae e Mimosoideae. Dentre as diversas tribos que compõem a subfamília Papilionoideae, figura a Dipteryxeae Polhill (Polhill, 1981; Oliveira \& Paiva, 2005).

Um dos gêneros mais representativos e estudados dessa tribo é o Pterodon composto de cinco espécies nativas brasileiras: Pterodon abruptus Benth., P. appariciori Pedersoli, P. emarginatus Vogel, $P$. polygalaeflorus Benth. e $P$. pubenscens Benth. (Almeida et al., 1998). Estudos fitoquímicos do gênero Pterodon têm revelado a presença de alcaloides na casca (Torrenegra et al., 1989), isoflavonas e alguns triterpenos no caule (Marques et al., 1998) e diterpenos (Fascio et al., 1976; Arriaga et al., 2000) e isoflavonas (Braz \& Gottlieb, 1971) em óleo das sementes. Os extratos alcoólicos obtidos a partir das sementes destas espécies são usados pela medicina popular como, antireumático, antiinflamatório e analgésico (Corrêa, 1975). Até 1980, ensaios biológicos com óleo dos frutos do gênero Pterodon, descritos na literatura, apresentaram atividade anti-cercária para as espécies $P$. appariciori, $P$. emarginatus, $P$. polygalaeflorus e $P$. pubescens; ação antimicrobiana in vitro e inibição do desenvolvimento de culturas de Crithidia fasciculata e Trypanosoma cruzi, para o óleo da espécie P. pubescens (Mors et al., 1967; Mahajan \& Monteiro, 1970; Fascio et al., 1976; Santos \& Sarti, 1980). Atividade Larvicida sobre Aedes aegypti e estudo fitoquímico de P. polygalaeflorus também é foco de outros estudos (Pimenta et al., 2006).

A espécie Pterodon emarginatus conhecida popularmente como sucupira-branca ou faveira é uma espécie arbórea, nativa do cerrado brasileiro, podendo ser encontrada nos Estados de Minas Gerais, São Paulo, Goiás e Mato Grosso do Sul, seu uso, destaca-se pela importância medicinal e florestal (Lorenzi, 2002).

Pela utilização popular brasileira, os extratos alcoólicos feitos, a partir, das sementes de P. emarginatus são usados como anti-reumático, antiinflamatório, problemas de coluna, depurativo e fortificante. Os frutos são usados para o tratamento de dores musculares, torções, artrite e artrose, apresentando ação antiinflamatória e analgésica (Mors et al., 1967). Na região Centro-oeste, a população utiliza o chá das cascas do caule para infecções ginecológicas (Almeida \& Gottlieb, 1975). O óleo dos frutos de P. emarginatus é aromático sendo usado também no combate ao reumatismo e diabetes. Carvalho (1998), a partir do extrato bruto dos frutos de $P$. emarginatus, verificou a atividade antiinflamatória desta espécie, atribuindo esta ação à presença de compostos terpênicos. Outros estudos mostram a ação protetora do extrato hexânico bruto dos frutos de P. emarginatus frente ao stress oxidativo e nitrosativo induzido por exercícios agudos em ratos (Paula et al., 2005). No extrato hexânico foram caracterizados ácidos graxos, sesquiterpenos
( $\alpha$-cariofileno, $\beta$-cariofileno, mirceno, $\alpha$-pineno, farneseno) e diterpenos tricíclicos furânicos com o isolamento do $6 \alpha, 7 \beta$-diacetoxivouacapan-17 $\beta$-oato de metila (Teixeira, 2003). Em estudos recentes realizados por Moraes (2007), foram isolados os triterpenos lupeol e betulina das frações hexânica e diclorometânica respectivamente, obtidas a partir do extrato etanólico bruto das cascas do caule, neste trabalho ainda foi verificada atividade antiinflamatória e antinociceptiva do referido extrato. A avaliação da atividade antimicrobiana dos extratos da casca foi realizada em bactérias patogênicas e na avaliação farmacognóstica detectou-se a presença de flavonoides, heterosídeos saponínicos, resinas, traços de esteróides e triterpenóides (Bustamante et al., 2005).

O estudo referente a óleos essenciais no gênero Pterodon restringe-se apenas ao obtido das sementes dos frutos, não havendo relato dos mesmos a partir de folhas. Portanto, desenvolveu-se este trabalho com o objetivo de analisar teor, composição química e atividade antimicrobiana do óleo essencial da folhas de $P$. emarginatus, além de isolar e identificar compostos ativos no extrato etanólico bruto de suas folhas.

\section{MATERIAL E MÉTODOS:}

\section{Material botânico, extração do óleo essencial e preparo do extrato etanólico}

Para a análise do óleo essencial e isolamento de fitoconstituintes de Pterodon emarginatus Vogel, Fabaceae, foram coletadas folhas no município de Bela Vista-GO (847 m de altitude, 17002'1,1" S/48049'0,3" W). A espécie foi identificada pelo Prof. Dr. José Realino de Paula e a exsicata encontra-se depositada no Herbário da Universidade Federal de Goiás sob o número UFG27.155 .

Após a coleta, as folhas, foram dessecadas em estufa com circulação forçada de ar a $40{ }^{\circ} \mathrm{C}$, por $48 \mathrm{~h} \mathrm{e}$ posteriormente submetidas à moagem em moinho de facas do tipo Willye. Para a extração do óleo essencial, 120 $\mathrm{g}$ do material botânico foi submetido à hidrodestilação em aparelho do tipo Clevenger por $2 \mathrm{~h}$. O volume de óleo essencial foi medido no tubo graduado do próprio aparelho e o rendimento em porcentagem, foi calculado em relação à quantidade inicial de pó empregado na extração. Para o preparo do extrato etanólico bruto o material pulverizado foi submetido a um processo de maceração a frio, por três dias, com agitação ocasional utilizando como líquido extrator, etanol $96{ }^{\circ} \mathrm{GL}$ PA. O extrato obtido foi concentrado em evaporador rotativo a uma temperatura de $40{ }^{\circ} \mathrm{C}$ (Ferri, 1996).

\section{Análise da composição química do óleo essencial}

O óleo essencial foi submetido à análise cromatográfica, em fase gasosa, acoplada à espectrometria 
de massas (CG/EM) em aparelho Shimadzu QP 5050A. Utilizou-se coluna capilar de sílica fundida (CBP-5; $30 \mathrm{~m}$ x $0,25 \mathrm{~mm}$ x $0,25 \mu \mathrm{m})$, mantendo fluxo de $1 \mathrm{~mL} / \mathrm{min}$ de Hélio, como gás de arraste, aquecimento com temperatura programada $\left(60{ }^{\circ} \mathrm{C} / 2 \mathrm{~min} ; 3{ }^{\circ} \mathrm{C} \mathrm{min}^{-1} / 240{ }^{\circ} \mathrm{C} ; 10^{\circ} \mathrm{C} \mathrm{min}^{-}\right.$ ${ }^{1} / 280{ }^{\circ} \mathrm{C} ; 280{ }^{\circ} \mathrm{C} / 10 \mathrm{~min}$ ) e energia de ionização de 70 eV. Injeção de $1 \mu \mathrm{L}$ da amostra diluída em $\mathrm{CH}_{2} \mathrm{Cl}_{2}$ na proporção de 1:5. Os componentes do óleo essencial foram identificados por comparação dos espectros de massa e índices de retenção com os descritos em literatura (Adams, 2007). Os índices de retenção foram calculados através da coinjeção de uma mistura de hidrocarbonetos C9- C22, e utilização da equação de Van Den Dool \& Kratz (1963).

\section{Avaliação da atividade antifúngica do óleo essencial das folhas de $P$. emarginatus}

Para a avaliação da atividade antifúngica in vitro do óleo essencial das folhas de $P$. emargintaus foi utilizado o método de microdiluição em caldo (NCCLS, 2002) nas concentrações de 1 a $512 \mu \mathrm{g} / \mathrm{mL}$ (triplicata) em cinco isolados de Candida pertencentes ao Laboratório de Micologia Médica do Instituto de Patologia Tropical e Saúde Pública-UFG. O óleo foi diluído em $1 \mathrm{~mL}$ de etanol até se obter uma concentração de $1024 \mu \mathrm{g} / \mathrm{mL}$.

Para o preparo do inóculo, cultivou-se a colônia de Candida em ágar Sabouraud a temperatura ambiente por $48 \mathrm{~h}$. Em seguida, fez-se a suspensão em salina estéril $0,85 \%(\mathrm{p} / \mathrm{v})$, sendo esta ajustada à escala $0,5 \mathrm{Mc}$ Farland, obtendo-se unidade formadora de colônia de 1.106. A concentração de células por $\mathrm{mL}^{2}$ foi de $5,0 \times 10^{2}$ a $2,5 \times 10^{3}$.

Para o preparo da microplaca, pipetou-se $100 \mu \mathrm{L}$ de RPMI em cada poço a partir da segunda fileira vertical. Na primeira fileira vertical, pipetou-se $200 \mu \mathrm{L}$ do óleo e a partir daí, fez-se a diluição sucessiva. Finalmente, em cada fileira horizontal, pipetou-se $100 \mu \mathrm{L}$ do inóculo. A placa foi incubada a $35{ }^{\circ} \mathrm{C}$ durante $48-72 \mathrm{~h}$. Como cepa padrão utilizou-se Candida parapsilosis ATCC 22019. Transcorrido o tempo necessário para o crescimento do inóculo, procedeu-se a leitura das placas.

Determinação da concentração inibitória mínima do óleo essencial das folhas de $P$. emarginatus em bactérias

A determinação da concentração inibitória mínima (CIM) foi realizada pelo método da diluição em ágar conforme recomendação do NCCLS (2003). Pela técnica foram obtidas placas (triplicata) contendo o óleo essencial em análise em concentrações que variaram de 50 até $0,78 \mathrm{mg} / \mathrm{mL}$. Prepararam-se também placas controle contendo o solvente (etanol), e ágar Müller Hinton. Foram utilizados, para este ensaio os seguintes microganismos: Bactérias Gram Positivas (Staphylococcus aureus
2592, Staphylococcus epidermidis 12228, Micrococcus roseus 1740, Micrococcus luteus ATCC 9341, Bacillus atropheus 6633, Bacillus cereus 14756, Bacillus stearothermophylus 1262) e bactérias Gram Negativas (Enterobacter cloaceae HMA/FT502, Enterobacter aerogenes ATCC 13048, Escherichia coli ATCC 8739, Escherichia coli ATCC 11225, Pseudomonas aeruginosa ATCC 9027 e Serratia marcescens ATCC 14756). As bactérias foram obtidas do Laboratório de Bacteriologia do Instituto de Patologia Tropical e Saúde Pública da Universidade Federal de Goiás. Estes microrganismos foram repicados para caldo tioglicolato e incubados a $37{ }^{\circ} \mathrm{C}$ por $24-48 \mathrm{~h}$ para reativação. Em seguida, foram repicados em placas ASI e incubados novamente a $37{ }^{\circ} \mathrm{C}$ por $24 \mathrm{~h}$. Após o desenvolvimento microbiano, inóculos de cada microrganismo foram suspensos em $2 \mathrm{~mL}$ de solução salina esterilizada $0,85 \%(\mathrm{p} / \mathrm{v})$ até obtenção de uma turvação correspondente a metade do tubo $\mathrm{n}^{\circ} 1 \mathrm{da}$ escala MacFarland. Transferiu-se $100 \mu \mathrm{L}$ de cada uma dessas suspensões para o inoculador de Steers (Steers et al., 1959) e aplicou-se na superfície das placas de Petri contendo as diluições do óleo em ágar Müller Hinton e os controles. As placas foram incubadas a $37^{\circ} \mathrm{C}$ por 24 h. Foi considerada CIM a menor concentração capaz de inibir o desenvolvimento microbiano.

\section{Extração, isolamento e caracterização dos esteróides}

Para a extração e isolamento dos constituintes do extrato etanólico bruto das folhas de P. emarginatus foi realizado o fracionamento de $10 \mathrm{~g}$ do extrato a partir de coluna filtrante de sílica gel 60 . Foram eluídos $100 \mathrm{~mL}$ de cada fase móvel: $n$-hexano, $n$-hexano/diclorometano $1: 1$, diclorometano, diclorometano/acetato de etila $1: 1$, acetato de etila, acetato de etila/metanol 1:1 e metanol, respectivamente. Dez frações de $10 \mathrm{~mL}$ para cada fase móvel aplicada foram obtidas.

A partir de análise em cromatografia de camada delgada (25DC-Alufolien 20x20 cm/Kieselgel $60 \mathrm{~F}_{254}$, Merck), revelação no ultravioleta nos comprimentos de onda 254 e $365 \mathrm{~nm}$ e reação com vanilina ácida, seguida de aquecimento $100{ }^{\circ} \mathrm{C}$, as frações que apresentaram o mesmo perfil cromatográfico foram reunidas em subfrações para posterior análise. As frações FHD6 a FHD8 (n-hexano:diclorometano 1:1) (200 mg) apresentaram perfil interessante em revelação à reação com vanilina ácida. Tais frações foram reunidas e renomeadas de $\mathrm{C} 1$. A nova fração foi submetida à cromatografia em coluna com Florisil ${ }^{\circledR}(0,150-0,250 \mathrm{~mm}$, Merck). Nesta análise foi usado como eluente $n$-hexano:acetato de etila (90:10) em sistema isocrático, coletando-se $10 \mathrm{~mL}$ para cada subfração. O novo fracionamento foi acompanhado por CCD e revelação com vanilina ácida, permitindo a reunião das seguintes frações: $\mathrm{C} 1.10$ a C1.13 $(68,1 \mathrm{mg})$, obtendo-se uma nova amostra codificada de $\mathrm{C} 2$ que foi submetida a coluna cromatográfica com sílica $\mathrm{MN}$ 
Kieselgel 60, usado como eluente $n$-hexano:acetato de etila (95:05) em sistema isocrático. Entre as subfrações C2.10 a C2.30 foram observados cristais de coloração branca. Após CCD em sistema eluente $n$-hexano: acetato de etila $15 \%$ com revelação em vanilina ácida foi possível detectar a presença de uma substância designada de S1 (C2.27 a C2.30), a qual foi caracterizada por Ressonância Magnética Nuclear de hidrogênio (RMN $\left.{ }^{1} \mathrm{H}\right)$ e de carbono $\left(\mathrm{RMN}{ }^{13} \mathrm{C}\right)$. As análises de RMN foram realizadas à temperatura ambiente em espectrômetro Mercury plus da Varian (7,05 T), utilizando uma sonda de $5 \mathrm{~mm}$ e pulsos de $45^{\circ}$ para o hidrogênio e carbono. Os deslocamentos químicos no RMN de ${ }^{1} \mathrm{H}(300 \mathrm{MHz})$ foram referenciados aos padrões internos TMS e para o solvente $\mathrm{CDCl}_{3}$. Nos espectros de $\mathrm{RMN}$ de ${ }^{13} \mathrm{C}(75,46$ $\mathrm{MHz}$ ), foram referenciados ao $\mathrm{CDCl}_{3}$.

\section{RESULTADOS E DISCUSSÃO}

O rendimento do óleo essencial em porcentagem $(\mathrm{p} / \mathrm{V})$ foi de $2 \%$. Os resultados da análise por CG/EM do óleo essencial extraído das folhas de P. emarginatus com os respectivos teores de cada componente expressos em porcentagem encontram-se descritos na Tabela 1, sendo todos eles hidrocarbonetos sesquiterpênicos. Essas substâncias apresentam atividade antibacteriana, antifúngica e antioxidante (Abraham, 2001). Em estudo realizado por Polo et al., (2004), a análise qualitativa e quantitativa do óleo essencial dos frutos de $P$. emarginatus evidenciou a presença dos constituintes: $\alpha$-pineno, mirceno, metil eugenol, etil eugenol, eugenol geraniol, cariofileno. Os compostos observados para o óleo essencial da folha diferem significativamente, sendo apenas o cariofileno comum para as amostras testadas. Análise da composição química do óleo essencial dos frutos de P. polygalaeflorus obtido por Campos et al., (1990), (ilangeno, $\alpha$-capaeno, $\beta$-cariofileno, $\alpha$-humuleno, $\gamma$-elemeno e $\delta$-cadineno) se assemelha à analise do óleo essencial das folhas de P. emarginatus efetuada no presente trabalho.

Tabela 1. Constituintes do óleo essencial das folhas de Pterodon emarginatus Vogel, Fabaceae.

\begin{tabular}{ccc}
\hline IR & Constituintes & Teor $(\%)$ \\
\hline 1376 & $\alpha$-copaeno & 1,07 \\
1390 & $\beta$-elemeno & 7,10 \\
1419 & $E$-cariofileno & 6,73 \\
1454 & $\alpha$-humuleno & 2,48 \\
1460 & allo-aromadendreno & 0,93 \\
1479 & $\gamma$-muuroleno & 48,79 \\
1500 & biciclogermacreno & 22,66 \\
1497 & acifileno & 7,41 \\
1523 & $\delta$-cadineno & 0,70 \\
\hline
\end{tabular}

IR: Índice de retenção; Rendimento: 2\%
No teste de suscetibilidade em microdiluição em caldo para determinar a atividade antifúngica (isolados de Candida) o resultado foi negativo, visto que o óleo nas concentrações testadas não inibiu os microrganismos utilizados.

No teste antimicrobiano realizado em bactérias os valores da concentração inibitória mínima (CIM) encontram-se expressos na Tabela 2. A atividade antibacteriana foi moderada frente a bactérias Grampositivas, e ausente para bactérias Gram-negativas. Devese levar em conta que a moderada atividade antimicrobiana da amostra analisada possa estar relacionada à baixa solubilidade do óleo no meio de cultura. Portanto, a solubilidade do óleo pode ter sido fator limitante para uma boa atividade antimicrobiana.

Tabela 2. Concentração inibitória mínima (CIM em $\mathrm{mg} / \mathrm{mL}$ ) do óleo essencial das folhas de Pterodon emarginatus Vogel, Fabaceae.

\begin{tabular}{lc}
\hline \multicolumn{1}{c}{ Microrganismos } & CIM \\
\hline \multicolumn{1}{c}{ Bactéria Gram-Positivas } & 50 \\
\hline Staphylococcus aureus 2592 & 12,5 \\
Staphylococcus epidermidis 12228 & 6,25 \\
Micrococcus roseus 1740 & 0,78 \\
Micrococcus luteus ATCC 9341 & 6,25 \\
Bacillus atropheus 6633 & 6,25 \\
Bacillus cereus 14756 & 6,25 \\
Bacillus stearothermophylus 1262 & \\
\hline \multicolumn{1}{c}{ Bactérias Gram-Negativas } & $>50$ \\
\hline Enterobacter cloaceae HMA/FT502 & $>50$ \\
Enterobacter aerogenes ATCC 13048 & $>50$ \\
Escherichia coli ATCC 8739 & $>50$ \\
Escherichia coli ATCC 11225 & $>50$ \\
Pseudomonas aeruginosa ATCC 9027 & $>50$ \\
Serratia marcescens ATCC 14756 &
\end{tabular}

Quanto à extração de fitocompostos, os sucessivos fracionamentos cromatográficos da fração $\mathrm{CH}_{2} \mathrm{Cl}_{2}$ obtida a partir do extrato etanólico bruto das folhas $(16,45 \%)$ em conjunto com análise dos espectros de RMN de ${ }^{1} \mathrm{H}$ e ${ }^{13} \mathrm{C}$, permitiu constatar que $\mathrm{S} 1(8,8 \mathrm{mg})$, trata-se de uma mistura de fitoesteróides $\beta$-sitosterol e estigmasterol de ampla ocorrência nos vegetais, cujas estruturas foram identificadas com base na análise de dados de RMN, bem como pela comparação com dados descritos na literatura (Kojima et al., 1990).

Mediante os resultados obtidos, pode-se inferir que o óleo essencial e os compostos isolados das folhas de P. emarginatus possuem potencial farmacológico, podendo ser exploradas para a obtenção de compostos bioativos.

\section{AGRADECIMENTOS}

À CAPES pela concessão da bolsa de Mestrado (APS), à Prof ${ }^{a}$. Dra. Inês Sabioni Resck do Departamento 
de Química da Universidade de Brasília (UnB) pela obtenção dos espectros de RMN, ao Prof. Dr. Pedro Henrique Ferri pelo auxílio com CG/EM e a Funape/ UFG.

\section{REFERÊNCIAS}

Abraham WR 2001. Bioactive sesquiterpenes produced by fungi: are they useful for humans as well? Curr Med Chem 8: 583-606.

Adams RP 2007. Identification of essential oil components by Gas Chromatography Mass Spectrometry. $4^{\text {th }}$ ed. Carol Stream, Illnois - USA: Allured Publishing Corporation.

Almeida ME, Gottlieb OR 1975. The chemistry of Brazilian Leguminosae. Further isoflavones from Pterodon apparicia. Phytochemistry 14: 2716.

Almeida SP, Proença CEB, Sano SM, Ribeiro JF 1998. Cerrado: Espécies Vegetais Úteis. Planaltina: EMBRAPA-CPAC, DF, $464 \mathrm{p}$.

Arriaga AMC, Castro MAB, Silveira ER, Braz- Filho R 2000. Further diterpenoids isolated from Pterodon polygalaeflorus. J Braz Chem Soc 11: 187-190.

Braz FR, Gottlieb OR 1971. Chemistry of Brazilian Leguminosae. XXXIV Isoflavones of Pterodon pubenscens. Phytochemistry 10: 2835-2836.

Bustamante KGL, Figueiredo ADL, Soares ML, Bara MTF, Ferreira HD, Rezende MH, Pimenta FC, Paula JR 2005. Estudo farmacognóstico e avaliação da atividade antimicrobiana da casca de Pterodon emarginatus Vog. (Fabaceae). In: Congresso de Pesquisa, Ensino e Extensão da UFG-CONPEEX, 2,. Anais eletrônico do II Seminário de Pequisa e Pós-Graduação (CD-ROM), Goiânia: UFG, 2005.

Campos AM, Craveiro AA, Teixeira TC 1990. Óleo essencial das sementes de Pterodon polygalaeflorus Benth. In: Resumos da Reunião da Sociedade Brasileira de Química, $\mathrm{PN}-004$.

Carvalho JCT 1998. Validação química-farmacológica da espécie vegetal Pterodon emarginatus Vog (atividade antiinflamatória), Dissertação de mestrado, São Paulo, Faculdade de Ciências Farmacêuticas, Universidade de São Paulo, 140 p.

Corrêa MP 1975. Dicionário das plantas úteis do Brasil $e$ das exóticas cultivadas. Instituto Brasileiro de Desenvolvimento Florestal, Rio de Janeiro, $153 \mathrm{p}$

Fascio M, Mors WB, Gilbert B, Mahajan JR, Monteiro MB, Santos FD, Wichnewsky W 1976. Diterpenoids furans from Pterodon pubescens species. Phytochemistry 15: 201-203.

Ferri PH 1996. Química de produtos naturais: métodos gerais. In: Di Stasi LC (Org.). Plantas medicinais: arte e ciência. São Paulo: Editora da Universidade Estadual Paulista, p. 129-156.

Judd WS, Campbell CS, Kellog EA, Stevens PF 1999. Plant Systematics: A Phylogenetic Approach. Massachusetts, Sinauer Associates.

Kojima H, Sato N, Hatano A, Ogura H 1990. Sterol glucosides from Prunella vulgaris. Phytochemistry 29: 23512355.

Lorenzi H 2002. Árvores Brasileiras, manual de identificação e cultivo de plantas arbóreas nativas do Brasil. Vol. 1, 4 ed, São Paulo, 242 p.
Mahajan JR, Monteiro MB 1970. New diterpenoids from Pterodon emarginatus Vog. An Ac Bras Cienc 42 (Suplemento): 103-107.

Marques DD, Machado MIL, Carvalho MG, Meleira LAC, BrazFilho F 1998. Isoflavonoids and triterpenoids isolated from Pterodon polygalaeflorus. J Braz Chem Soc 9: 295301.

Mendonça RC, Felfili JM, Walter BMT, Silva MC, Rezende AV, Filgueiras AV, Nogueira PE 1998. Flora Vascular do Bioma Cerrado. In Cerrado: Ambiente e flora.

Moraes WF 2007. Estudo fitoquímico e avaliação das atividades analgésica e antiinflamatória do extrato etanólico, frações e substância isolada da casca do caule de Pterodon emarginatus Vog. (sucupira). Goiânia, 104 p. Dissertação de Mestrado, Programa de Pós-graduação em Ciências Farmacêuticas, Universidade Federal de Goiás.

Mors WB, Santos FMF, Monteiro HJ, Gilbert B 1967. Chemoprophylatic agent in schistossomiasis: 14,15epoxygeranilgeraniol. Science 157: 950-951.

NCCLS 2002. Método de referência para teste de diluição em caldo para determinação da sensibilidade de leveduras à terapia antifúngica. M27-A2.

NCCLS 2003. Methods for dilution antimicrobial susceptibility tests for bacteria that grow aerobically. Villanova, PA: National Committee for Clinical Laboratory Standards.

Oliveira DMT, Paiva EAS 2005. Anatomy and ontogeny of Pterodon emarginatus (Fabaceae: Faboideae) seed. Braz J Biol 65: 483-494.

Paula FBA, Gouvêa CMCP, Alfredo, PP, Salgado I 2005. Protective action of a hexane crude extract of Pterodon emarginatus fruits against oxidative and nitrosative stress induced by acute exercise in rats. BMC Complement Altern Med 5: 1-9.

Pimenta ATM, Santiago GMP, Arriaga AMC, Menezes GHA, Bezerra SB 2006, Estudo fitoquímico e avaliação da atividade larvicida de Pterodon polygalaeflorus Benth (Leguminosae) sobre Aedes aegypti. Rev Bras Farmacogn 16: 501-505.

Polhill RM 1981. Advances in Legume Systematics. Royal Botanic Gardens, Kew.

Polo M, Carvalho JCT, Mesquista, JMO, Sarti SJ, Santos-Filho D, Sertiê JAA 2004. Caracterização fitoquímica do extrato bruto hexânico e do óleo essencial dos frutos da espécie Pterodon emarginatus Vog. Rev Esc Farm Odontol Alfenas 26: 45-49.

Ratter JA, Ribeiro JF, Briggewater S 1997. The Brazilian cerrado vegetation and threats to its biodiversity. Ann Bot 80: 223-230.

Santos FD, Sarti SJ 1980. Lactona diterpênica de Pterodon pubescens Benth: Atividade inibitória do desenvolvimento de Crithidia fasciculata e do Trypanosoma cruzi, in vivo. Rev Fac Farm Odontol Ribeirão Preto 17: 69-72.

Solereder H 1908. Systematic Anatomy of the Dicotyledons: A handbook for laboratories of pure and applied Botany. Oxford: Clarendon Press, vol. I, p. 253-301.

Souza VC, Lorenzi H 2005. Botânica Sistemática: Guia Ilustrado para Identificação das Famílias de Angiospermas da Flora Brasileira, baseado em APG II. Nova Odessa, Plantarum.

Steers E, Foltz EL, Graaves VS 1959. An inocula replicatingapparatus for continue testing of bacterial 
susceptibility to antibiotics. Antibiot Chemoter 9: 307311.

Teixeira DF 2003. Estudo químico e avaliação biológica de Attalea excelsa Mart. ex Spreng. (urucuri) e Pterodon emarginatus Vog. (Sucupira-branca) em Aedes aegypti. Rio de Janeiro, 154 p. Dissertação de Mestrado, Programa de Pós-graduação em Ciências Farmacêuticas, Universidade Federal do Rio de Janeiro.

Torrenegra R, Bauereib, Achenbach H 1989. Homoormosaninetype alkaloids from Bowdichia virgilioides. Phytochemistry 28: 2219-2221.

Van Den Doll H, Kratz PDJA 1963. Generalization of the retention index system including linear temperature programmed gas-liquid partition chromatography. $J$ Chromatogr 11: 463-471. 